\title{
Immunization with a Mixture of HIV Env DNA and VLP Vaccines Augments Induction of CD8 T Cell Responses
}

\author{
Ling Ye, ${ }^{1}$ Zhiyuan Wen, ${ }^{1,2}$ Ke Dong, ${ }^{1,3}$ Lei Pan, ${ }^{1,4}$ Zhigao Bu, ${ }^{2}$ Richard W. Compans, ${ }^{1}$ \\ Huizhong Zhang, ${ }^{3}$ and Chinglai Yang ${ }^{1}$ \\ ${ }^{1}$ Department of Microbiology \& Immunology, Emory Vaccine Center, Emory University School of Medicine, 1510 Clifton Road, \\ Room 3086 Rollins Research Center, Atlanta, GA 30322, USA \\ ${ }^{2}$ Agriculture Ministry Key Laboratory of Veterinary Public Health, Harbin Veterinary Research Institute, CAAS, \\ 427 Maduan Street, Harbin 150001, China \\ ${ }^{3}$ Central Laboratory, Tangdu Hospital, The Fourth Military Medical University, No. 1 Xinsi Road, Xi'an 710038, China \\ ${ }^{4}$ Department of Infectious Diseases, Tangdu Hospital, The Fourth Military Medical University, No. 1 Xinsi Road, \\ Xi'an 710038, China
}

Correspondence should be addressed to Chinglai Yang, chyang@emory.edu

Received 30 November 2009; Revised 27 February 2010; Accepted 2 March 2010

Academic Editor: Hanchun Yang

Copyright ( 2010 Ling Ye et al. This is an open access article distributed under the Creative Commons Attribution License, which permits unrestricted use, distribution, and reproduction in any medium, provided the original work is properly cited.

\begin{abstract}
The immune response induced by immunization with HIV Env DNA and virus-like particle (VLP) vaccines was investigated. Immunization with the HIV Env DNA vaccine induced a strong CD8 T cell response but relatively weak antibody response against the HIV Env whereas immunization with VLPs induced higher levels of antibody responses but little CD8 T cell response. Interestingly, immunization with a mixture the HIV Env DNA and VLP vaccines induced enhanced CD8 T cell and antibody responses. Further, it was observed that the mixing of DNA and VLP vaccines during immunization is necessary for augmenting induction of CD8 T cell responses and such augmentation of CD8 T cell responses was also observed by mixing the HIV Env DNA vaccine with control VLPs. These results show that immunization with a mixture of DNA and VLP vaccines combines advantages of both vaccine platforms for eliciting high levels of both antibody and CD8 T cell responses.
\end{abstract}

\section{Introduction}

Since the identification of the human immunodeficiency virus (HIV) as the causative agent of AIDS twenty-five years ago, tremendous amount of effort has been poured into vaccine development. However, despite the significant progress that has been made over the last two decades, an efficacious AIDS vaccine strategy is still elusive. Earlier clinical trials using HIV Env-based subunit vaccines failed to show significant protection against HIV infection or disease progression [1-3]. Subsequent studies in nonhuman primates showed that induction of a strong cellular immune response against SIV and HIV antigens, particularly a strong cytotoxic CD8 T cell response, was able to exert a successful control of disease progression and AIDS development [4-7]. However, despite the promising results obtained in animal studies, the results from a recent clinical trial of a T-cellbased vaccine regimen dealt another setback to AIDS vaccine development [8]. The disappointing outcomes from these vaccine trials further reinforce the notion that an effective AIDS vaccine should be able to induce both strong antibody and cytotoxic T cell responses against HIV [9-12].

A number of studies have shown that DNA vaccines can effectively induce both antibody and $\mathrm{T}$ cell responses against their encoded antigens $[13,14]$. DNA immunization induces immune responses through both direct transfection of antigen presenting cells (APCs) and cross priming of APCs $[14,15]$ and offers several advantages over other vaccine platforms. First, the direct in vivo expression of antigens by DNA vaccination renders it more effective in eliciting cellular immune responses than protein-based vaccines, as in vivo synthesized antigens are processed and presented through both major histocompatibility complex I and II for inducing both CD4 and CD8 T cell responses. Second, expression of the antigens over a long period of time after DNA vaccination may provide sustained stimulation of the immune system for 
inducing long lasting immune responses [16]. Third, DNA vaccines can be applied repeatedly without inducing immune responses against the vector in contrast to recombinant viralvector-based vaccines.

Virus-like particles (VLPs) represent another attractive concept for vaccine development [17-19]. VLPs share with DNA vaccines the ability to be administered repeatedly to vaccinated individuals. The nonreplicative nature of VLPs and their lack of viral genomic RNA make them safe for broad and repeated application. Since the assembly and arrangement of viral glycoproteins in VLPs resemble intact virions, they are likely to be more effective in inducing neutralizing antibodies as compared with soluble antigens. Earlier studies have shown that a viral glycoprotein presented in a highly repetitive form in virus particles is more potent in inducing $\mathrm{B}$ cell response and antibody production than the same antigen presented in a poorly organized form [20,21]. In several studies, HIV VLPs have been shown to induce both neutralizing antibodies and CTL responses to HIV antigens $[22,23]$.

While both the HIV DNA and VLP vaccines can induce antibody as well as cytotoxic $\mathrm{T}$ cell responses [12, 24, 25], DNA vaccines induce immune responses through direct in vivo antigen synthesis whereas VLP vaccines directly present viral glycoproteins on the surface of a particulate antigen. As a result of their different properties, immune responses induced by these two vaccine platforms are likely to be different. In this study, we compared the immunogenicity of HIV Env-DNA and VLP vaccines and investigated whether a combination of these two vaccine platforms may complement each other when given as a mixture for inducing both antibody and CD8 $\mathrm{T}$ cell responses.

\section{Materials and Methods}

2.1. Preparation of DNA and VLP Vaccines. The HIV 89.6 Env718Tr/Y710S DNA construct, designated as Env-DNA, has been described in previous studies [26] For large-scale preparation, the plasmids were amplified in E. coli DH5 $\alpha$ and purified with a Qiagen Endo-Free Megaprep kit. The plasmids were then resuspended at $1 \mu \mathrm{g} / \mu \mathrm{l}$ in sterile PBS and stored at $-80^{\circ} \mathrm{C}$ until used for immunization. Construction of recombinant baculoviruses expressing the SIV Gag (rBVGag) and the HIV 89.6 Env protein (rBV-Env) has also been described previously [27, 28]. SHIV 89.6 VLPs were produced by coinfection of Sf9 insect cells with $\mathrm{rBV}-\mathrm{Gag}$ and rBV-Env at a multiplicity of 2 and 5, respectively. At 60 hours post infection, medium from infected cells was collected and clarified of cell debris by centrifuge at 7,000 rpm in a Sorvall SS-34 rotor for 20 minutes. The VLPs in the supernatant were concentrated by ultracentrifugation at $28,000 \mathrm{rpm}$ for 1 hour in a Beckman SW28 rotor, resuspended in PBS, and further purified by centrifugation through a discontinuous sucrose gradient $(20 \%, 35 \%$, and $50 \%$ layers $)$ at $30,000 \mathrm{rpm}$ for 1 hour in a Beckman SW41 rotor. The band that contained VLPs (between 35\% and 50\% layers) was collected, concentrated, and then resuspended in PBS at a final concentration of $2 \mu \mathrm{g} / \mu \mathrm{l}$. The integrity of purified VLPs was examined by electron microscopy and the presence of SIV
Gag and HIV 89.6 Env proteins in VLP preparations was determined by western blot analysis as described previously [28]. Protein concentration of the VLP preparation was determined by a BCA protein assay (Pierce Biotechnology, Rockford, IL) and the amount of HIV 89.6 Env proteins in the VLP preparation were determined by a sandwich ELISA using purified HIV 89.6 gp120-Histag as standards. The VLP preparation was stored in $-80^{\circ} \mathrm{C}$ until immunization and the same VLP preparation was used in the immunization experiments throughout this study. The SIV Gag only VLPs were produced by infection of Sf9 cells with rBV-Gag at the multiplicity of 2 and purified similarly as described above.

2.2. Immunization of Mice. Female BALB/c mice (H-2d) 6-8 weeks of age were purchased from Charles River Laboratory. Mice were housed in the animal facility operated by the Division of Animal Resources at Emory University. All procedures were carried out following animal research guidelines and approved by IACUC. For immunization with DNA or VLP vaccines alone, groups of mice (six mice per group) were immunized with $50 \mu \mathrm{g}$ DNA or VLPs dissolved in $100 \mu \mathrm{l}$ PBS per mouse by intramuscular injection in both side quadriceps with $50 \mu \mathrm{l}$ of the preparations at each side. For immunization with a mixture of DNA and VLPs, $50 \mu \mathrm{g}$ DNA and $50 \mu \mathrm{g}$ VLPs were mixed in $100 \mu \mathrm{l}$ PBS prior to immunization and then administered to mice by intramuscular injection in both side quadriceps with $50 \mu \mathrm{l}$ of the preparations at each side. For immunization with both DNA and VLP vaccines at separate sites, $50 \mu \mathrm{g}$ DNA or $50 \mu \mathrm{g}$ VLPs were each dissolved in $50 \mu \mathrm{l}$ PBS and administered to mice by intramuscular injection in separate side quadriceps respectively. Mouse blood samples were collected by retroorbital bleeding at 14 days after each immunization, heatinactivated, and stored at $-80^{\circ} \mathrm{C}$ until analysis. All mice received a boosting immunization at 4 weeks after priming following the same procedure.

2.3. Flow Cytometry Analysis of CD8 T Cell Responses. Analysis of cellular immune responses by intracellular cytokine staining and flow cytometry was carried out as described previously $[29,30]$. Immunized mice were sacrificed two weeks after the second immunization and mouse splenocytes were prepared with lysis of red blood cells with ammonium chloride and washed twice with RPMI 1640. The cells were resuspended in complete culture medium (RPMI 1640 plus $10 \%$ fetal calf serum, $50 \mu \mathrm{M}$ beta-mercaptoethanol, and antibiotics mix) and the cell viability was determined by trypan blue exclusion. Cells $\left(10^{6}\right)$ were cultured in the presence of brefeldin A (Sigma, $10 \mu \mathrm{g} / \mathrm{mL}$ ), with a stimulating peptide corresponding to a CTL epitope of the HIV89.6 Env protein (IGPGRARYAR, $10 \mu \mathrm{g} / \mathrm{mL}$ ) or an irrelevant peptide corresponding to a segment in the HIV Gag protein (AMQMLKETI, negative control) for 6 hours. After stimulation with peptide, the cells were washed twice with PBS containing 3\% fetal calf serum and then stained with FITC-conjugated rat anti-CD8 and PerCP-conjugated rat anti-CD4 antibodies (Pharmingen). Cells were then fixed and permeabilized with cytofix buffers (Caltag) and then 
stained for intracellular IFN $\gamma$ using APC conjugated rat antiIFN $\gamma$ antibody (Pharmingen). Flow cytometry analysis was performed on a BD FACSCalibre with CELLQuest software.

2.4. ELISA. ELISA plates were coated with purified HIV-1 89.6 gp120-Histag (prepared by Nicald affinity purification using a Qiagen kit, at $2 \mu \mathrm{g} / \mathrm{mL}$ in borate-buffered saline, $\mathrm{pH} 8.5,100 \mu \mathrm{l}$ per well) at $4^{\circ} \mathrm{C}$ overnight and blocked with PBS-T-BSA (phosphate-buffered saline, $0.1 \%$ tween$20,3 \%$ bovine serum album) for 3 hours at $37^{\circ} \mathrm{C}$. Serial dilutions of mouse serum were then added to each well in triplicate and incubated at $37^{\circ} \mathrm{C}$ for 3 hours. HRPconjugated secondary antibody (Sigma) against mouse IgG, IgG1, or IgG2a was added for 2 hours at $37^{\circ} \mathrm{C}$. After a final wash, ABTS (2,2'-azino-bis(3-ethybenz-thiazoline-6sulfonic acid), Sigma) dissolved in citrate phosphate buffer ( $3 \mathrm{mg}$ ABTS in $10 \mathrm{~mL} \mathrm{CPB}$, pH 4.2, plus $10 \mu \mathrm{l} \mathrm{H}_{2} \mathrm{O}_{2}$ ) was added at $100 \mu \mathrm{l} /$ well for developing color and read by an ELISA reader at $405 \mathrm{~nm}$. A standard curve for absorbance and the amount of mouse antibody absorbed to the well were obtained by coating ELISA plates with serial 2-fold dilutions of purified mouse antibodies followed by addition of HRP-conjugated secondary antibody and development of color. Data were analyzed by a Microsoft Excel program and presented as the equivalent amount of Env-binding antibodies in mouse sera $(\mathrm{ng} / \mathrm{mL})$ and statistical analysis was carried out using Student $t$-test.

2.5. Sedimentation Assay. To determine whether the DNA and VLPs bind to each other in the DNA and VLP mixture, we carried out a sedimentation study. The HIV Env-DNA $(50 \mu \mathrm{g})$ and DNA and VLP mixture $(50 \mu \mathrm{g}$ DNA plus $50 \mu \mathrm{g}$ VLP) were loaded onto a two-layer sucrose cushion, with $500 \mu \mathrm{l} 30 \%$ sucrose at bottom and $2 \mathrm{~mL} 20 \%$ sucrose above, followed by centrifugation at 30,000 RPM for 30 minutes in a Beckmann SW55Ti rotor. To determine whether the integrity of VLPs is necessary for binding to DNA molecules, we also included a control sample in which VLPs $(50 \mu \mathrm{g})$ were lysed by $1 \%$ Triton X-100 prior to mixing with the HIV Env-DNA $(50 \mu \mathrm{g})$. VLPs $(50 \mu \mathrm{g})$ only were also included as a negative control. After centrifugation, top layers were removed from the tube and the concentration of DNA molecules in the $30 \%$ sucrose cushion was determined by UV spectrometry at OD260. The relative amount and mobility of DNA in the $30 \%$ sucrose cushion was also examined by electrophoresis in an agarose gel.

2.6. Bone Marrow-Derived Dendritic Cell (BMDC) Preparation and Stimulation. Mouse BMDCs were prepared following procedures as reported by Lutz et al. in their studies [31]. Briefly, femurs were obtained from sacrificed mice and the marrows were flushed out with FACS medium and then filtered through a cell strainer. After lysis of red blood cells, bone marrow leukocytes were resuspended in FACS medium and cell numbers were counted by trypan blue staining. The leukocytes were then seeded in $100 \mathrm{~mm}$ bacteriological petri dishes at $2 \times 10^{6}$ per dish in $10 \mathrm{~mL}$ FACS medium containing $20 \mathrm{ng} / \mathrm{mL}$ recombinant mouse GM-CSF. On day 3, another
$10 \mathrm{~mL}$ FACS medium containing $20 \mathrm{ng} / \mathrm{mL}$ recombinant mouse GM-CSF was added to each dish. On day 6, half of the culture supernatant was collected, centrifuged, and the cell pellet resuspended in $10 \mathrm{~mL}$ fresh FACS medium containing $20 \mathrm{ng} / \mathrm{mL}$ recombinant mouse GM-CSF and then added back into the original dish. Analysis by flow cytometry shows that BMDCs prepared by this method are over 70\% CD11c positive. On day 7 of culture, $10^{5} \mathrm{BMDCs}$ were added to each well in a 96-well plate and stimulated in vitro with HIV EnvDNA $(50 \mu \mathrm{g} / \mathrm{mL})$, SHIV 89.6 VLPs $(10 \mu \mathrm{g} / \mathrm{mL})$, a mixture of DNA $(50 \mu \mathrm{g} / \mathrm{mL})$, and VLPs $(10 \mu \mathrm{g} / \mathrm{mL})$, as well as with LPS ( $10 \mathrm{ng} / \mathrm{mL}$, positive control) or mock-treated media (negative control) in triplicates. In parallel, the samples were also heated at $100^{\circ} \mathrm{C}$ for 30 minutes before being added to DCs in the stimulation assay. Supernatants were harvested after 24 hours of incubation at $37^{\circ} \mathrm{C}$ in $5 \% \mathrm{CO}_{2}$, and cytokine levels in cell supernatants were measured by ELISA in duplicates using commercially available kits (eBioscience) for IL-6, IL-12, as well as TNF-alpha according to the manufacturer's instruction. For detection of CD80 and CD86 surface expression, BMDCs were harvested after stimulation by DNA or VLP vaccines as described above and the cells were washed twice with PBS containing 3\% fetal calf serum. After wash, the cells were stained with PE conjugated rat antiCD11c and APC conjugated rat anti-CD80 (or anti-CD86) antibodies (Pharmingen). Cells were then fixed with cytofix buffers (Caltag) and then analyzed by flow cytometry on a BD FACSCalibre with CELLQuest software.

\section{Results}

3.1. HIV Env-DNA and VLP Vaccines Exhibit Different Abilities to Induce CD8 T Cell and Antibody Responses. Construction and characterization of the HIV 89.6 Env718Tr/Y710S DNA vaccine (designated as the Env-DNA in this study) has been described previously [30]. SHIV 89.6 VLPs were produced by coinfection of Sf9 insect cells with recombinant baculoviruses expressing the HIV 89.6 Env and SIVmac239 Gag proteins, respectively. As shown in Figure 1(a), both HIV 89.6 Env and SIV Gag proteins were detected in SHIV 89.6 VLPs by Western blot. Examination of purified VLPs by electron microscopy showed that they exhibit a uniformed spherical morphology that is about $150 \mathrm{~nm}$ in diameter and similar in size to HIV virions (Figure 1(b)). The amount of HIV Env proteins in SHIV 89.6 VLP preparations was further determined by a sandwich ELISA using purified HIV Env gp120 as a standard and the results showed that there is about 100-130 ng HIV Env proteins in $5 \mu \mathrm{g}$ of three different SHIV 89.6 VLP preparations (Figure 1(c)). After production and characterization, the SHIV 89.6 VLPs were used in immunization studies in comparison with the HIV Env-DNA vaccine as outlined in Figure 2. The plasmid DNA vector pCAGGS and SIV Gag-VLPs that were produced by infection of Sf9 insect cells with recombinant baculoviruses expressing the SIVmac239 Gag protein were used as control DNA and VLPs, respectively, in the immunization studies.

As shown in Figure 3, immunization with the EnvDNA vaccine alone (Group 2) induced significant levels of CD8 $\mathrm{T}$ cell responses against the HIV Env with an 


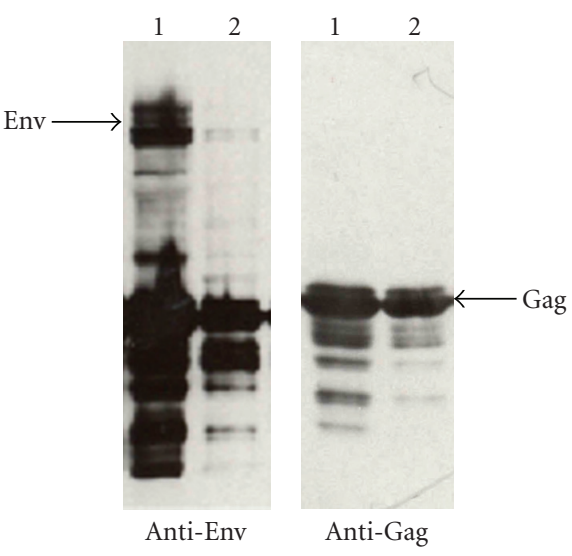

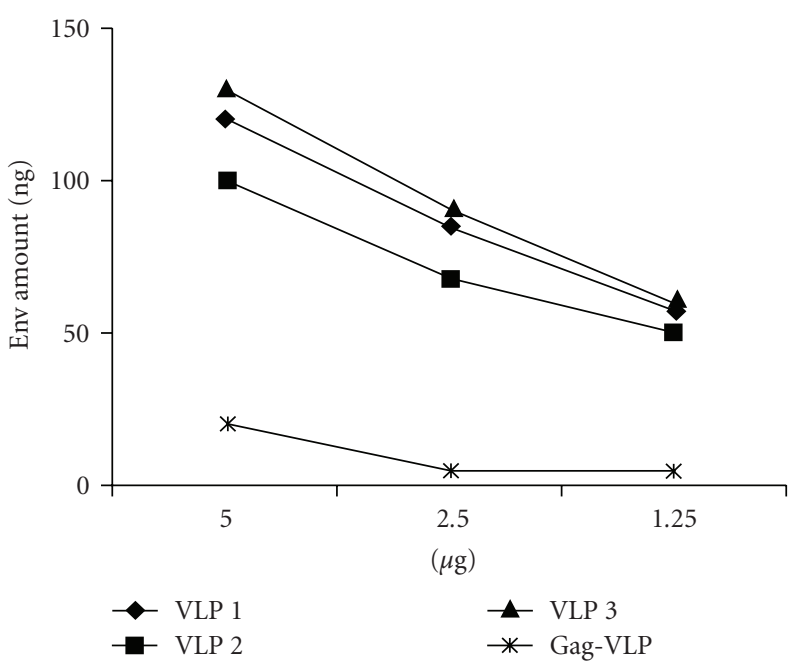

(b)

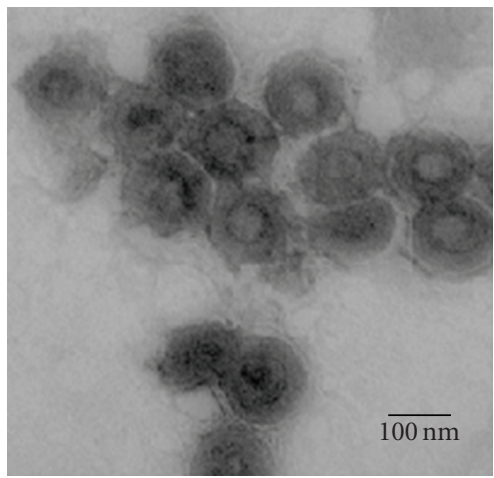

(c)

Figure 1: Characterization of SHIV 89.6 VLPs. SHIV 89.6 VLPs were produced by coinfection of Sf9 cells with rBVs expressing HIV 89.6 Env and SIVmac239 Gag proteins at the MOI (multiplicity of infection) of 5 and 2, respectively, and purified as described in Section 2. SIV Gag VLPs were produced by infection of Sf9 cells with rBV expressing SIVmac239 Gag proteins and purified similarly. (a) Characterization of SHIV 89.6 VLPs by Western blot. $5 \mu \mathrm{g}$ total proteins were taken from each VLP preparation and analyzed by SDS-PAGE followed by Western blot using rabbit-anti-gp120 antibody for detection of HIV Env proteins and monkey-anti-SIV fordetection of the SIV Gag proteins. Lanes 1, SHIV 89.6 VLP; 2, SIV Gag-only VLP. (b) Comparison of HIV 89.6 Env amount in VLP preparations by a quantitative ELISA. The amount of HIV Env proteins in SHIV 89.6 VLP preparations was determined by a sandwich ELISA. ELISA plates were coated with a sheep-antigp120 antibody as the capture antibody, followed by addition of serial 2-fold dilutions of SHIV 89.6 VLPs lysed by $1 \%$ Triton X-100. The amount of HIV Env bound to the plate was then detected by sera from HIV-infected patients as the detecting antibody, followed by addition of HRP-conjugated Goat-antihuman antibody and development of color. Lysed SIVmac239 Gag VLPs were used as controls. A standard curve for the amount of HIV Env was obtained by adding purified HIV 89.6 Gp120 mixed with SIVmac239 Gag VLP lysed by 1\% Triton X-100 to the sheep-anti-gp120 antibody-coated ELISA plate. The amount of HIV Env proteins was then calculated based on the obtained standard curve and then expressed as nanograms (ng) of HIV Env in $1 \mu \mathrm{g}$ VLP preparation. VLP1, VLP2, and VLP3 represent SHIV 89.6 VLPs produced from three different batches and Gag-VLP represents the control SIVmac239 Gag only VLP preparation. (c) Negative staining and EM examination of SHIV 89.6 VLPs. Purified SHIV 89.6 VLPs were stained with $1 \%$ uranyl acetate followed by examination under a transmission electron microscope.

average of about $0.8 \%$ total CD8 $\mathrm{T}$ cells stimulated to produce interferon-gamma by a peptide corresponding to a dominant epitope in the HIV Env protein. In contrast, no significant level of $\mathrm{CD} 8 \mathrm{~T}$ cell response against the HIV Env was induced by immunization with SHIV 89.6 VLPs alone (Group 3) compared to the control group that was immunized with a mixture of plasmid DNA vector pCAGGS and SIV Gag-VLPs (Group 1). On the other hand, immunization with SHIV 89.6 VLPs induced higher levels of antibody responses against the HIV Env gp120, which is almost twofold higher on average compared to the HIV Env-DNA vaccine (Figure 4(a)). We further compared the levels of IgG1 and IgG2a antibody subtypes against the HIV Env gp120 induced by the HIV Env-DNA and VLP vaccines. As shown in Figures 4(b) and 4(c), immunization with the HIV Env-DNA and SHIV 89.6 VLPs induced similar levels 


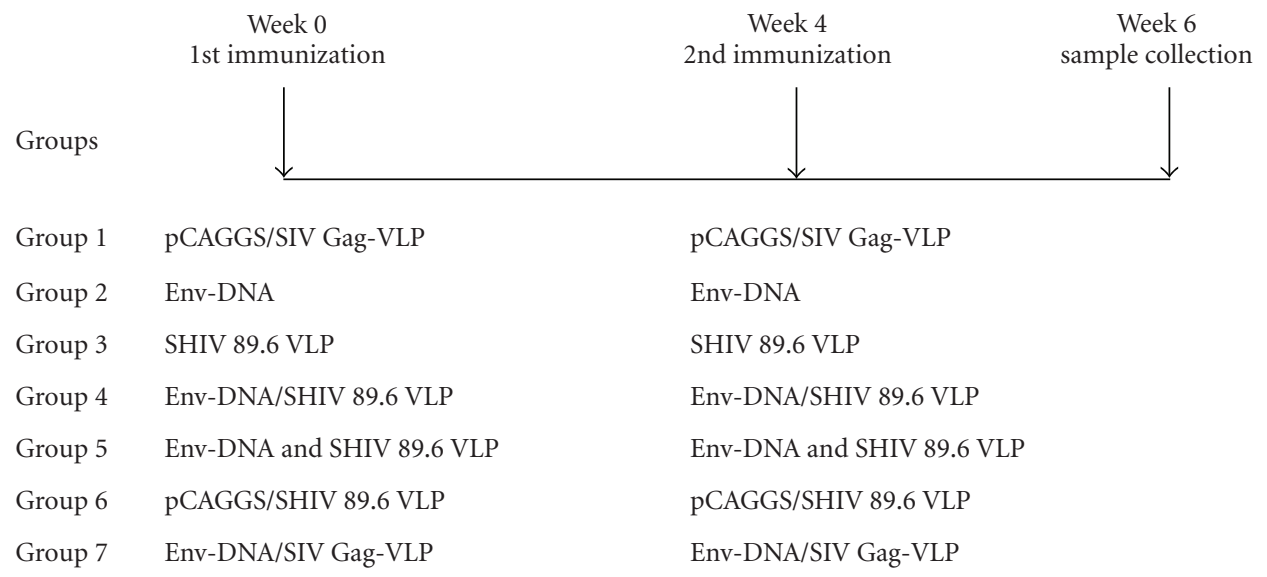

FIGURE 2: Schematic diagram of immunization study design. Six groups of mice (groups of 6) were immunized with different vaccine preparations as indicated. Group 1: a mixture of $50 \mu \mathrm{g}$ DNA vector pCAGGS and $50 \mu \mathrm{g}$ SIV Gag-VLPs; Group 2: $50 \mu \mathrm{g}$ HIV Env-DNA; Group 3: $50 \mu \mathrm{g}$ SHIV 89.6 VLPs; Group 4: a mixture of $50 \mu \mathrm{g}$ HIV Env-DNA and $50 \mu \mathrm{g}$ SHIV 89.6 VLPs; Group 5: simultaneous injection with $50 \mu \mathrm{g}$ HIV Env-DNA and $50 \mu \mathrm{g}$ SHIV 89.6 VLPs at separate sites; Group 6: a mixture of $50 \mu \mathrm{g}$ pCAGGS DNA vector and $50 \mu \mathrm{g}$ SHIV 89.6 VLPs; Group 7: a mixture of $50 \mu \mathrm{g}$ HIV Env-DNA and $50 \mu \mathrm{g}$ SIV Gag-VLPs. Mice were immunized twice by intramuscular injections at weeks 0 and 4 , and sacrificed at week 6 (two weeks after the second immunization) to collect blood samples and prepare splenocytes for analysis of immune responses.

of IgG1 antibodies against the HIV Env gp120. However, the level of IgG2a antibodies induced by SHIV 89.6 VLPs was significantly higher than that induced by the Env DNA vaccine. Taken together, these results show that the HIV EnvDNA vaccine is more potent in eliciting CD8 T cell responses whereas the SHIV 89.6 VLPs is more effective in eliciting antibody responses against the HIV Env.

3.2. Immunization with a Mixture of the HIV Env-DNA and VLP Vaccines Induces Enhanced CD8 T Cell Responses. Comparison of immune responses induced by HIV EnvDNA and VLP vaccines showed that these two different vaccine platforms exhibit different abilities in eliciting CD8 $\mathrm{T}$ cell and antibody responses. We therefore further investigated whether a combination of these two vaccines may complement each other. As outlined in Figure 2, mice in Group 4 were immunized with a mixture of HIV EnvDNA and VLP vaccines. In addition, we also included three additional groups that were immunized by simultaneous injection of the HIV Env-DNA vaccine and SHIV 89.6 VLPs at separate sites (Group 5), by a mixture of SHIV 89.6 VLPs and the DNA vector pCAGGS (Group 6), and by a mixture of the HIV Env-DNA vaccine and the control SIV Gag-only VLPs (Group 7), respectively, for comparison. As shown in Figure 3, immunization with a mixture of HIV Env-DNA and VLP vaccines (Group 4) induced an average of about $2 \%$ total CD8 $\mathrm{T}$ cells against the Env, more than twofold higher than the level induced in Group 2 mice that were immunized by the HIV Env-DNA vaccine alone $(P<.05)$. On the other hand, immunization by separate injections of the HIV Env-DNA and SHIV 89.6 VLPs (Group 5 ) induced an average of about $0.9 \%$ total CD8 T cells against the HIV Env, similar to the level induced by immunization with the HIV Env-DNA vaccine alone (Group 2). Moreover, immunization with a mixture of the HIV Env-DNA vaccine and control SIV Gag-VLPs (Group 7) induced an average of about $1.6 \%$ total CD8 T cells against the HIV Env that is also significantly higher $(P<.05)$ compared to the levels induced by immunization with the HIV Env-DNA vaccine alone (Group 2) or by separate injections of HIV Env-DNA and SHIV 89.6 VLPs (Group 5). In contrast, no significant CD8 $\mathrm{T}$ cell response was induced by immunization with a mixture of SHIV 89.6 VLPs and the DNA vector pCAGGS (Group 6) similar as observed for mice immunized with SHIV 89.6 VLPs alone (Group 3), further demonstrating the weakness of VLPs for eliciting CD8 T cell responses. These results indicate that VLPs may exert an adjuvant activity and augment induction of CD8 T cell responses by the HIV EnvDNA vaccine. Moreover, administering the HIV Env-DNA and VLPs in a mixture is necessary for eliciting enhanced CD8 T cell responses.

3.3. Induction of Higher Levels of Antibody Responses Does Not Require Mixing of the HIV Env DNA and VLP Vaccines during Immunization. Analysis of antibody responses revealed a different outcome compared to the CD8 T cell responses. As shown in Figure 4, immunization with the Env-DNA and SHIV 89.6 VLP mixture (Group 4) induced higher levels of antibody responses on average than immunization with either the HIV Env-DNA (Group 2) or the SHIV 89.6 VLP vaccine (Group 3 ) alone. However, statistical analysis showed that the antibody response induced by the vaccine mixture (Group 4) is only significantly higher than the antibody responses induced by the HIV Env-DNA vaccine (Group 2). Further, while immunization by separate injections of the HIV Env-DNA and SHIV 89.6 VLPs (Group 5) did not augment induction of CD8 T cell responses, it induced higher levels of antibody responses against the HIV Env compared to immunization with the HIV Env-DNA vaccine alone (Group 2), similar to those induced by immunization with 

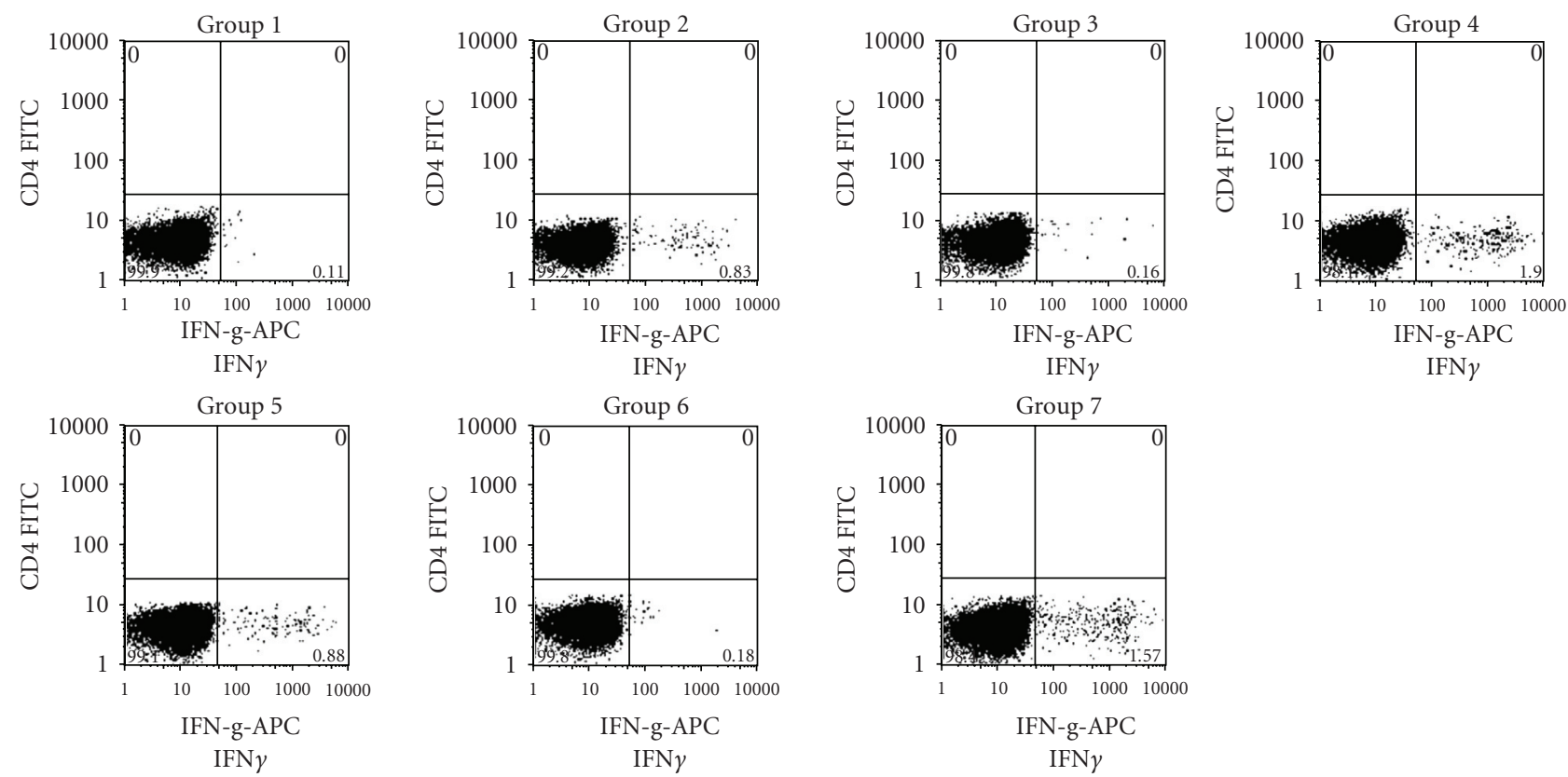

(a)

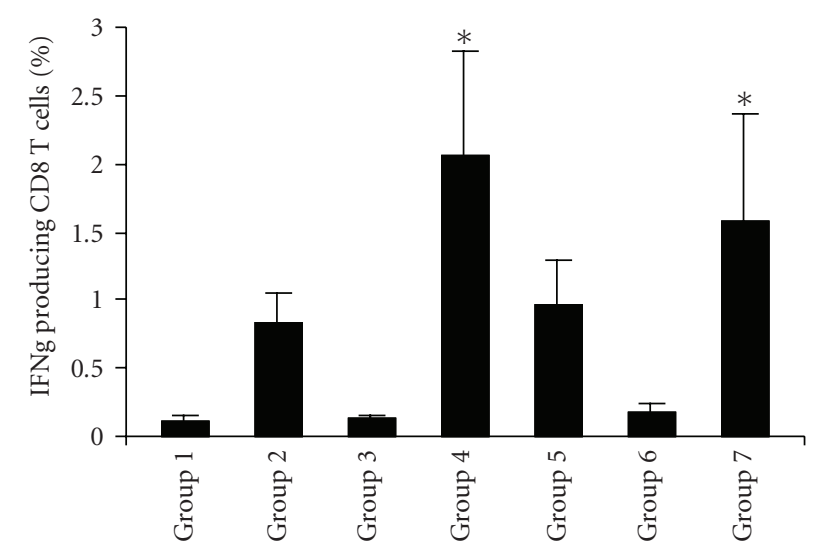

(b)

FIGURE 3: Enhanced CD8 T cell responses by immunization with a mixture of HIV Env-DNA and SHIV 89.6 VLPs but not by simultaneous injection at separate sites. Groups of mice ( 6 per group) were immunized by intramuscular injection at weeks 0 and 4 with different vaccine preparations as shown in Figure 2. Two weeks after the second immunization, mouse splenocytes were prepared and stimulated by the peptide IGPGRAFYAR corresponding to the dominant CD8 epitope in the HIV Env for Balb/c mice. The percentages of IFN $\gamma$-producing CD8 T cells were analyzed by intracellular-cytokine staining and flow cytometry. (a) Representative results of FACS analysis for IFN $\gamma$ producing CD8 T cells from each immunization group stimulated with the peptide IGPGRAFYAR. Numbers in lower-right boxes represent percentages of IFN $\gamma$ staining positive CD8 T cells. Background levels of IFN $\gamma$-producing CD8 T cells similar to Group 1 were obtained for all samples stimulated with an irrelevant peptide AMQMLKETI (data not shown). (b) Percentages of IFN $\gamma$ staining positive CD8 T cells for each immunization group after stimulation with the peptide IGPGRAFYAR. Error bars represent standard deviations for each group. $*$ indicates the groups with significantly higher levels of CD8 T cell responses than Group 2 that received the HIV Env-DNA vaccine only $(P<.05)$.

the mixture of HIV Env-DNA and VLP vaccines (comparing Group 4 and Group 5). On the other hand, while immunization with a mixture of the HIV Env-DNA vaccine and SIV Gag-VLPs induced enhanced CD8 T cell responses, it did not augment induction of antibody responses against the HIV Env. In fact, the average level of antibody response induced by immunization with a mixture of the HIV Env-DNA vaccine and SIV Gag-VLPs is lower compared to that induced by immunization with the HIV Env-DNA vaccine alone for both IgG1 and IgG2a antibodies (comparing Group 7 with Group 2). Moreover, the antibody response against the HIV Env induced by immunization with a mixture of SHIV 89.6 VLPs and the control DNA vector pCAGGS is similar to that induced by immunization with SHIV 89.6 VLPs alone (compare Group 3 and Group 6). Taken together, these results indicate that in contrast to induction of CD8 T cell responses, 


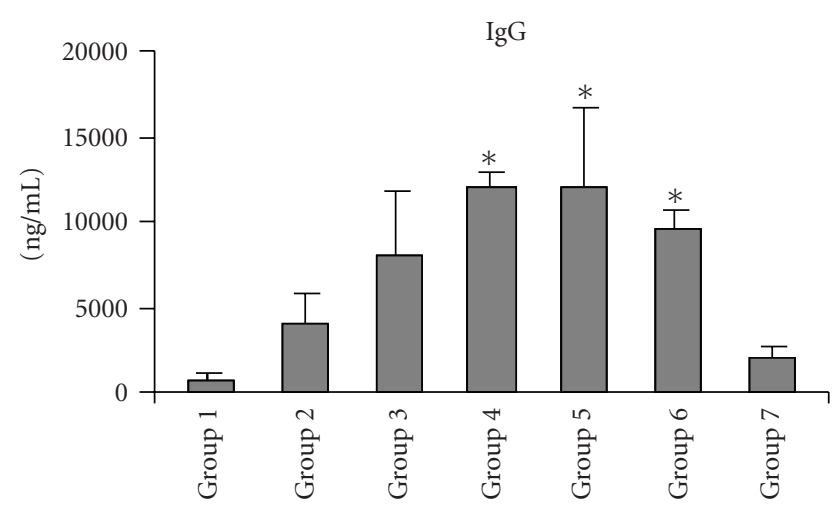

(a)

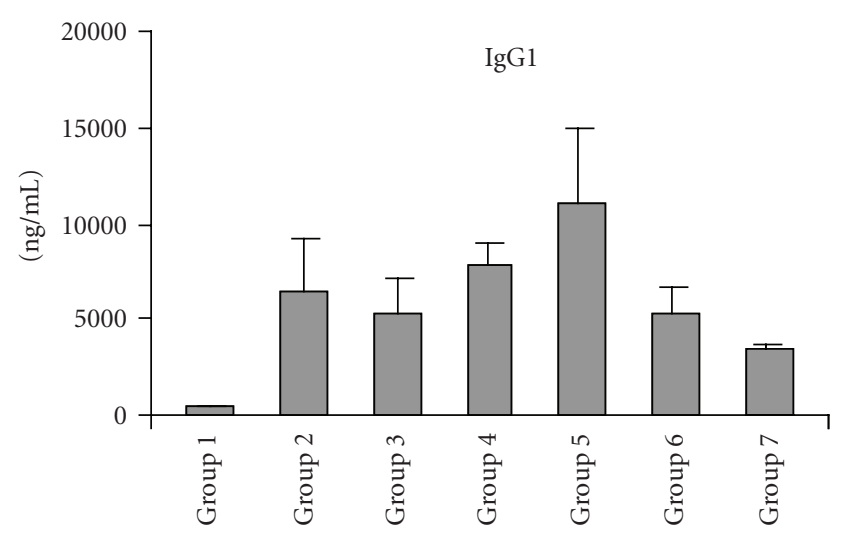

(b)

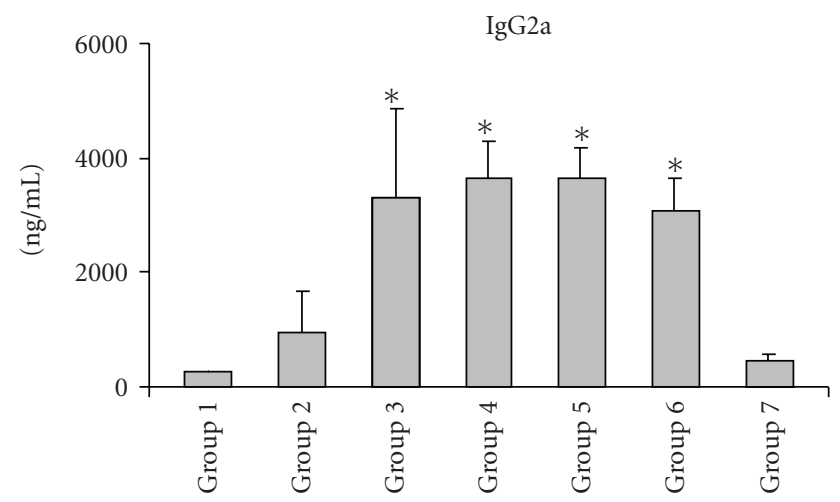

(c)

Figure 4: Comparison of antibody responses induced by immunization with the HIV Env-DNA and SHIV 89.6 VLP vaccines in different combinations. Mice were immunized by different vaccine preparations as described in Figure 2. Sera were collected at 2 weeks after the second immunization and analyzed for antibodies specific for HIV 89.6 gp120 by ELISA. The levels of antibody responses are expressed as the quantity (ng) of antibodies binding to HIV 89.6 gp120 in $1 \mathrm{~mL}$ sera from each mouse. (a) Total IgG antibodies against gp120. (b) IgG1 subtype antibodies against gp120. (c) IgG2a subtype antibodies against gp120. Error bars indicate the standard deviations for each immunization group. $*$ indicates the groups with significantly higher levels of antibody responses than Group 2 that received the HIV Env-DNA vaccine only $(P<.05)$. the HIV Env-DNA and VLP vaccines do not exert an adjuvant activity to each other for eliciting antibody responses. Of note, while both SHIV 89.6 VLPs and HIV Env-DNA vaccines induced similar levels of IgG1 antibody responses, immunization with VLPs induced significantly higher levels of IgG2a antibodies that are over 4-fold higher compared to the HIV Env-DNA vaccine $(P<.05)$. Moreover, this is similarly observed for all groups that received SHIV 89.6 VLPs in immunization (Groups 3, 4, 5, and 6) versus those that received HIV Env-DNA but no SHIV 89.6 VLPs in immunization (Groups 2 and 7). These results demonstrate that the profiles of the antibody response induced by the HIV EnvDNA and VLP vaccines are different and the IgG2a antibodies were primarily induced by VLPs in immunization with a mixture of HIV Env-DNA and SHIV 89.6 VLP vaccines.

\subsection{VLPs Bind to DNA Molecules in the DNA and VLP Mix-} ture and Exhibit Dendritic Cell- (DC-) Stimulating Activities. The results from above studies showed that VLPs augmented induction of CD8 $\mathrm{T}$ cell responses by the HIV Env-DNA vaccine and the adjuvant effect was only observed when VLPs and HIV Env-DNA are given as a mixture during immunization. To delineate the underlying mechanism, we first investigated whether DNA molecules bind to VLPs in the mixture by using a sedimentation assay. The HIV EnvDNA, SHIV 89.6 VLP, or their mixture was overlaid on top of a $30 \%$ sucrose cushion, and after centrifugation, the relative amount of DNA in the bottom 30\% sucrose cushion was examined by electrophoresis in an agarose gel. To determine whether the integrity of VLPs affects binding with DNA molecules, we also included a mixture of HIV Env-DNA and lysed-VLPs for comparison. As shown in Figure 5(a), the amount of DNA detected in the sample containing the DNA and VLP mixture is much higher compared to those detected in samples containing DNA only or DNA mixed with lysed VLPs. Further, the DNA molecules in the sample containing the DNA and VLP mixture also exhibited a slower mobility, which may result from the formation of aggregates through binding to VLPs. These results indicate that DNA and VLPs are bound to each other in the mixture and the binding is dependent on the integrity of VLPs.

Previous studies have shown that SHIV 89.6 VLPs exhibit DC-stimulating activities [32]. We thus further investigated whether SHIV 89.6 VLPs stimulate cytokine secretion by DCs when mixed with DNA molecules. As shown in Figure 5(b), incubating DCs with SHIV 89.6 VLPs or a mixture of HIV Env-DNA and SHIV 89.6 VLPs effectively stimulated secretion of cytokines IL-6, IL-12, as well as TNF-alpha to similar levels as incubating DCs with bacteria LPS. On the other hand, incubating DCs with HIV EnvDNA molecules only did not stimulate significant levels of cytokine secretion as compared to unstimulated DCs. The stimulation of DCs by SHIV 89.6 VLPs is not due to contamination of bacteria endotoxin as boiled-SHIV 89.6 VLPs or HIV Env-DNA mixed with boiled-SHIV 89.6 VLPs did not stimulate cytokine secretion. In contrast, boiling does not affect the ability of LPS to stimulate cytokine secretion by DCs. We further determined surface expression of costimulatory molecules CD80 and CD86 on DCs after 


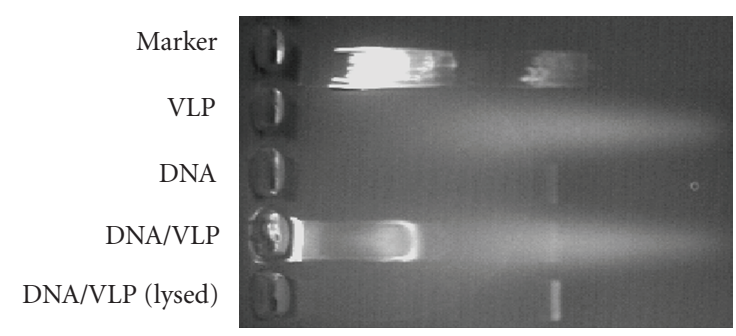

(a)
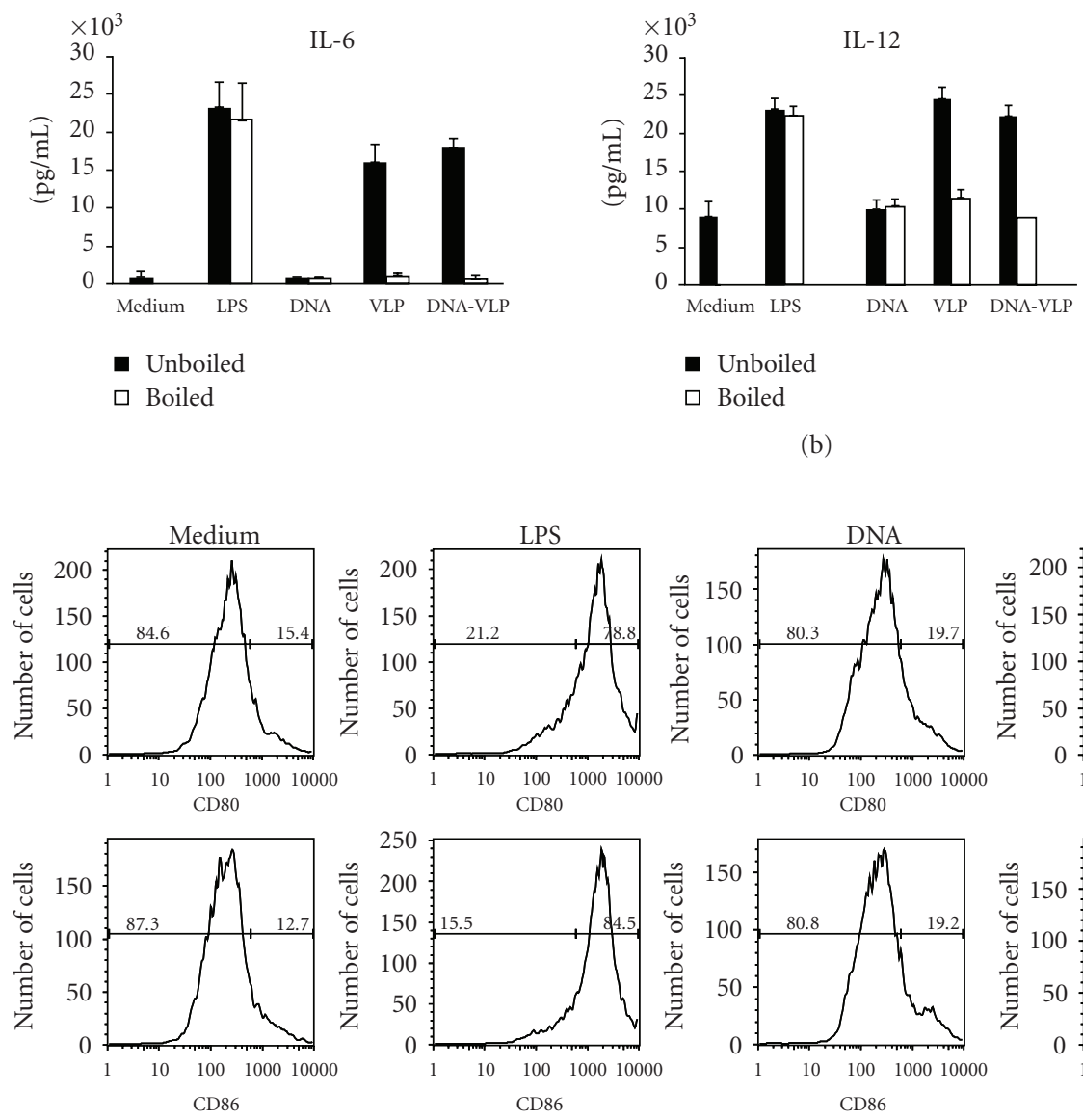

(b)
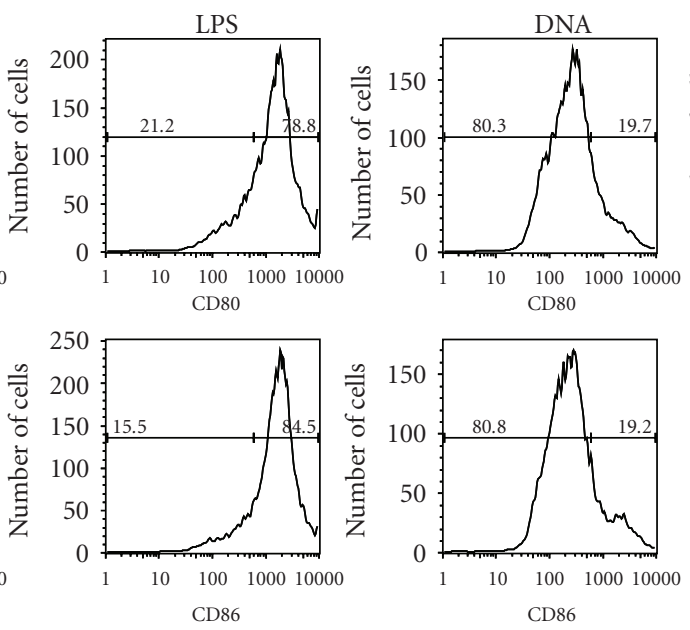

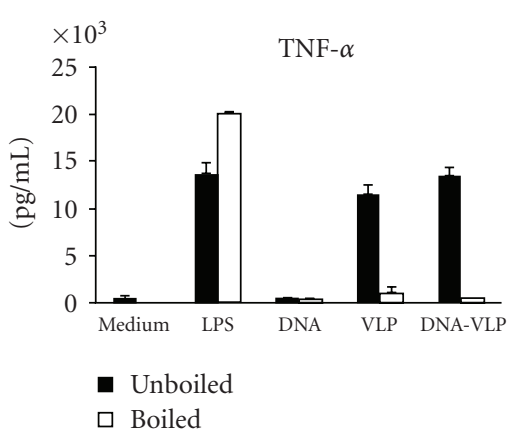

Unboiled
$\square$ Boiled
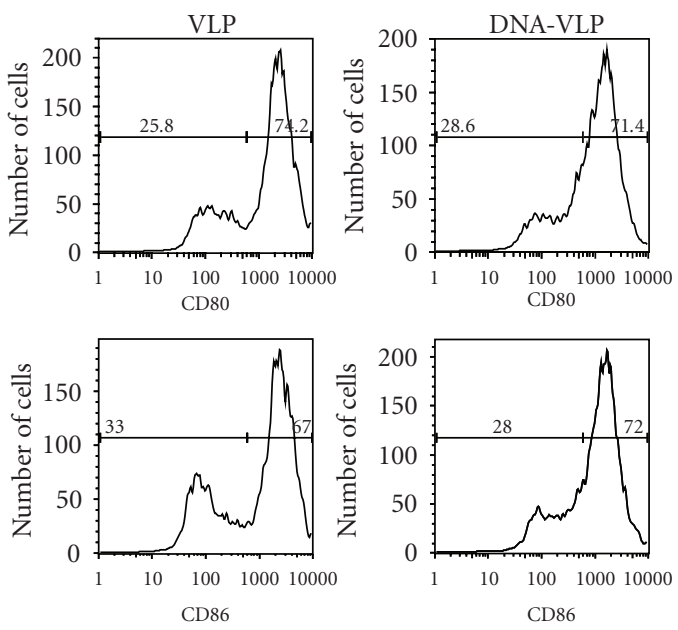

(c)

Figure 5: (a) DNA molecules bind to VLPs in the DNA/VLP mixture. HIV 89.6 Env-DNA, SHIV 89.6 VLPs, or their mixtures were loaded onto a two-layer sucrose cushion, with $500 \mu \mathrm{l} 30 \%$ sucrose at bottom and $2 \mathrm{~mL} 20 \%$ sucrose above, followed by ultracentrifugation. After centrifugation, $10 \mu \mathrm{l}$ from the $30 \%$ cusion of each sample was loaded onto a $1 \%$ agarose gel, and after electrophoresis, the gel was stained with Ethidium Bromide followed by destaining and then visualization of DNA by UV light. Marker: DNA molecular weight marker (lambda DNA Hind III digest); VLP: $50 \mu \mathrm{g}$ SHIV 89.6 VLPs; DNA: $50 \mu \mathrm{g}$ HIV Env-DNA; DNA/VLP: $50 \mu \mathrm{g}$ HIV Env-DNA mixed with $50 \mu \mathrm{g}$ SHIV: 89.6 VLPs; DNA/VLP (lysed): $50 \mu \mathrm{g}$ HIV Env-DNA mixed with $50 \mu \mathrm{g}$ SHIV 89.6 VLPs that were lysed with 1\% Triton X-100. (b) SHIV 89.6 VLPs stimulate cytokine secretion by BMDCs. BMDCs were prepared as described in Section 2 and incubated with different stimulants in triplicates. DCs incubated with culture medium only were used as negative controls and DCs incubated with LPS (10 ng/mL) were used as positive controls. To ensure that stimulation of DC by DNA or VLPs is not due to contamination of endotoxin, the DCs were also incubated with the same stimulants that have been heat-treated at $100^{\circ} \mathrm{C}$ for 30 minutes. Cell-free supernatants were harvested 24 hours after incubation at $37^{\circ} \mathrm{C}$ in $5 \% \mathrm{CO}_{2}$ and assayed for the levels $(\mathrm{pg} / \mathrm{mL}$ ) of IL-6, IL-12, and TNF-alpha by ELISA. Error bars represent standard deviations and the results shown represent typical results obtained from two different stimulation experiments. Medium, cell culture medium (negative control): LPS, $10 \mathrm{ng} / \mathrm{mL}$ (positive control); DNA: HIV Env-DNA (50 $\mu \mathrm{g} / \mathrm{mL})$; VLP: SHIV 89.6 VLPs $(10 \mu \mathrm{g} / \mathrm{mL})$; DNA-VLP: a mixture of HIV Env-DNA $(50 \mu \mathrm{g} / \mathrm{mL})$ and SHIV 89.6 VLPs $(10 \mu \mathrm{g} / \mathrm{mL})$. (c) Maturation of BMDCs after stimulation by SHIV 89.6 VLP vaccines. BMDCs were incubated with different stimulants as described above. After stimulation, the BMDCs were stained for surface expression of CD11c, CD80, and CD86 and then analyzed by flow cytometry. The results are presented as histograms for CD80 (upper panel) and CD86 (lower panel) for CD11c positive cells. Medium: cell culture medium (negative control); LPS: $10 \mathrm{ng} / \mathrm{mL}$ (positive control); DNA: HIV Env-DNA $(50 \mu \mathrm{g} / \mathrm{mL})$; VLP: SHIV 89.6 VLPs $(10 \mu \mathrm{g} / \mathrm{mL})$; DNA-VLP: a mixture of HIV Env-DNA $(50 \mu \mathrm{g} / \mathrm{mL})$ and SHIV $89.6 \mathrm{VLPs}(10 \mu \mathrm{g} / \mathrm{mL})$. 
stimulation. As shown in Figure 5(c), stimulation of DCs by VLPs or the DNA-VLP mixture significantly increased the surface expression of CD80 and CD86 that is comparable to stimulation by LPS. In contrast, incubation of DCs with DNA vaccine alone did not induce upregulation of CD 80 and CD86 surface expression similar to the use of medium alone. These results show that the VLPs are highly potent in DCstimulation compared to DNA molecules, and this property of VLPs may also be responsible for their adjuvant activity to augment induction of $\mathrm{CD} 8 \mathrm{~T}$ cell responses by the HIV Env-DNA vaccine when given as a mixture.

\section{Discussion}

The advancement in molecular biology and biomedical research has led to the development of new vaccine strategies against virus infection. Among these are DNA and VLP vaccines that both have attracted great interest for HIV vaccine development [33]. Both DNA and VLP vaccines share the ability to be administered repetitively for boosting induction of immune responses without the concern for preexisting or induced antivector immune responses. However, information on direct comparison of these two different vaccine platforms for inducing antibody and CD8 T cell responses is still lacking. In this study, we evaluated immune responses induced by the HIV Env-DNA and SHIV 89.6 VLP vaccines for comparison and investigated the effectiveness of their combination for inducing both antibody and CD8 T cell responses.

The results from this study showed that immunization with the HIV Env-DNA vaccine induced significant levels of CD8 $\mathrm{T}$ cell responses, similar as observed in our previous studies [30]. The potency of DNA vaccines to induce $\mathrm{CD} 8 \mathrm{~T}$ cell responses is probably due to direct in vivo antigen synthesis after DNA immunization, which are more efficiently presented to the MHC I antigen presentation pathway for eliciting CD8 T cell responses [14]. In contrast, immunization with SHIV 89.6 VLPs induced minimal to undetectable levels of CD8 T cell responses against the HIV Env, indicating that the VLPs are relatively poor inducers of $\mathrm{CD} 8 \mathrm{~T}$ cell responses similar as inactivated virus vaccines as well as other protein-based vaccines [2]. Of note, previous studies have shown the induction of CTL responses against the HIV Env by HIV or SHIV VLPs [24, 25, 32]. However, the immune response induced by VLPs was not compared with other vaccine platforms such as DNA vaccines in those studies and the CTL responses were assessed by assay for cytolytic activity of $\mathrm{T}$ cells after in vitro stimulation. Thus, it is possible that VLPs can elicit low levels of CD8 T cell responses that become detectable after in vitro stimulation as shown in early studies $[24,25,32]$. On the other hand, the $\mathrm{CD} 8 \mathrm{~T}$ cell responses were investigated in this study by direct ex vivo stimulation with a peptide corresponding to the dominant CD8 epitope in the HIV Env. Moreover, previous studies in nonhuman primates have shown that DNA vaccines are more effective than VLPs for induction of $\mathrm{T}$ cell responses against the HIV Gag protein [34]. Taken together, these results show that the HIV DNA vaccines are more effective than the VLPs for eliciting CD8 T cell responses.
On the other hand, SHIV 89.6 VLPs were found to induce higher levels of antibody responses compared to the HIV Env-DNA vaccine. Interestingly, further analysis of antibody responses showed that the profiles of antibody responses induced by the HIV Env DNA vaccines and VLPs are different. While both SHIV 89.6 VLPs and the the HIV Env-DNA vaccine induced similar levels of IgG1 antibody responses, immunization with VLPs induced significantly higher levels of IgG2a antibodies that are over 4-fold higher compared to the HIV Env-DNA vaccine. Moreover, this is similarly observed for all groups that received SHIV 89.6 VLPs in immunization (Groups 3, 4, 5, and 6) versus those that received HIV Env-DNA but no SHIV 89.6 VLPs in immunization (Groups 2 and 7), indicating that the IgG2a antibodies are primarily induced by immunization with SHIV 89.6 VLPs. The underlying mechanism for antibody subtype switch is still not clear and evidence suggests that a number of factors such as antigen forms as well as immunization routes may affect the levels of IgG2a antibodies [35, 36]. It has been reported that intramuscular immunization with plasmid DNAs expressing ovalbumin or hen egg lysozyme induced higher levels of IgG2a antibodies than immunization with purified soluble proteins [37]. In addition, it has also been shown that immunization with the secreted monomer hepatitis B virus e antigens induced predominantly IgG1 antibodies whereas immunization with the particulate hepatitis B virus core antigens elicited mostly IgG2a and IgG2b antibodies [38]. Moreover, it has been recently reported than VLPs can directly activate conventional $\mathrm{B}$ cells and promote $\mathrm{B}$ cell differentiation to IgG2a producing plasma cells [39]. Thus, it is possible that the presentation of multiple Env protein complexes on the surface of VLPs, which are particulate antigens, is more effective in eliciting $\operatorname{IgG} 2 \mathrm{a}$ antibody responses. The induction of enhanced IgG2a antibody responses indicates a Th1-oriented immune response, which has been suggested to be more effective in complement activation for lysis of virus-infected cells $[37,40]$. It will be interesting to investigate whether the induction of Th1 type antibody responses may provide additional benefit to the control of HIV infection through more effective complement fixation and antibody-dependent cell cytotoxicity (ADCC) to clear virus infected cells.

Of particular interest to vaccine development, we found that immunization with a mixture of the HIV Env-DNA with VLP vaccines significantly augmented induction of CD8 $\mathrm{T}$ cell responses compared to immunization with the HIV Env-DNA vaccine alone. Further, the enhancement in CD8 $\mathrm{T}$ cell responses was only observed in mice immunized with a mixture of the HIV Env-DNA vaccine with VLPs but not in mice immunized by separate injections. These results indicate that the VLPs in the vaccine mixture exert an adjuvant effect on the induction of CD8 T cell responses by the HIV Env-DNA vaccine. A number of studies have shown that using liposomes to absorb DNA vaccines enhances induction of immune responses by increasing uptake of DNA vaccines by host cells [41]. In this study, we found that the DNA plasmids bind to VLPs in the DNA and VLP mixture. Thus, the observed adjuvant activity of VLPs on DNA vaccines may result from increased uptake of DNA 
vaccines in a mixture with VLPs by host cells, particularly by antigen-presenting cells (APCs) such as dendritic cells (DCs) that are more efficient in taking up particulate antigens $[42,43]$. On the other hand, we also observed that SHIV 89.6 VLPs as well as their mixture with HIV Env-DNA potently stimulate cytokine secretion by DCs, and such stimulation is not observed for the HIV Env-DNA alone. Thus, it is possible that the VLPs may also augment induction of CD8 T cell responses by HIV Env-DNA through stimulating APCs for more effective antigen presentation. In contrast to CD8 $\mathrm{T}$ cell responses, immunization with the mixture of HIV Env-DNA and SHIV 89.6 VLPs induced similar levels of antibody responses to those induced by injecting HIV EnvDNA and SHIV 89.6 VLPs at separate sites. Further, mixing the HIV Env-DNA vaccine with SIV Gag VLPs actually reduced induction of antibody responses despite a significant enhancement in CD8 $\mathrm{T}$ cell responses. This discrepancy suggests that the underlying mechanisms for the induction of antibody and CD8 T cell responses by the HIV EnvDNA vaccine are likely to be different. It is possible that the VLPs in the mixture may target DNA molecules to specific cell populations that are more specialized in stimulating CD8 $\mathrm{T}$ cell responses. Alternatively, it is also possible that augmented CD8 T cell responses may kill DNA-transfected APCs through their cytotoxic activities and thus reduce antigen production for antibody induction. Nonetheless, the induction of strong antibody responses by the mixture of HIV Env-DNA and VLP vaccines indicates that the VLPs effectively compensate for the reduced ability of DNA vaccines to elicit antibody responses in such a setting.

In summary, comparison of immune responses induced by HIV Env-DNA and VLP vaccines showed that these two vaccine platforms exhibit different abilities in eliciting antibody and CD8 T cell responses. Further, immunization with a mixture of HIV Env-DNA and VLP vaccines is able to induce both strong antibody and CD8 $\mathrm{T}$ cell responses as compared with immunization with either vaccine alone, indicating that this approach combines the advantages of DNA and VLP vaccines with respect to their abilities to induced antibody and CD8 T cell responses. Moreover, VLPs also exert an adjuvant activity on induction of CD8 T cell responses by DNA vaccines when given as a mixture and such an adjuvant activity is also observed for irrelevant control VLPs, indicating that this approach may also apply other DNA and VLP vaccines for obtaining similar results. The induction of both strong antibody and CD8 T cell responses by immunization with a mixture of DNA and VLP vaccines may be applied to the development of more effective vaccine strategies against HIV or other viruses for which an effective control will require both antibody and CD8 T cell responses.

\section{Acknowledgments}

This work was supported in part by research Grants from the National Institute of Health AI44405, AI47018, and AI060406, and funding from the Emory University Global Health Institute.

\section{References}

[1] J. Cohen, "Clinical research. A setback and an advance on the AIDS vaccine front," Science, vol. 300, no. 5616, pp. 28-29, 2003.

[2] R. N. Germain and D. H. Margulies, "The biochemistry and cell biology and antigen processing and presentation," Annual Review of Immunology, vol. 11, pp. 403-450, 1993.

[3] P. Pitisuttithum, P. Gilbert, M. Gurwith, et al., "Randomized, double-blind, placebo-controlled efficacy trial of a bivalent recombinant glycoprotein $120 \mathrm{HIV}-1$ vaccine among injection drug users in Bangkok, Thailand," Journal of Infectious Diseases, vol. 194, no. 12, pp. 1661-1671, 2006.

[4] R. R. Amara, F. Villinger, J. D. Altman, et al., "Control of a mucosal challenge and prevention of AIDS by a multiprotein DNA/MVA vaccine," Science, vol. 292, no. 5514, pp. 69-74, 2001.

[5] D. H. Barouch, et al., "Vaccine-elicited immune responses prevent clinical AIDS in SHIV(89.6P)-infected rhesus monkeys," Immunology Letters, vol. 79, no. 1-2, pp. 57-61, 2001.

[6] N. F. Rose, P. A. Marx, A. Luckay, et al., "An effective AIDS vaccine based on live attenuated vesicular stomatitis virus recombinants," Cell, vol. 106, no. 5, pp. 539-549, 2001.

[7] J. W. Shiver, T.-M. Fu, L. Chen, et al., "Replicationincompetent adenoviral vaccine vector elicits effective antiimmunodeficiency-virus immunity," Nature, vol. 415, no. 6869, pp. 331-335, 2002.

[8] F. Miedema, "A brief history of HIV vaccine research: stepping back to the drawing board?" AIDS, vol. 22, no. 14, pp. 1699$1703,2008$.

[9] D. R. Burton, R. C. Desrosiers, R. W. Doms, et al., "HIV vaccine design and the neutralizing antibody problem," Nature Immunology, vol. 5, no. 3, pp. 233-236, 2004.

[10] N. L. Letvin and B. D. Walker, "Immunopathogenesis and immunotherapy in AIDS virus infections," Nature Medicine, vol. 9, no. 7, pp. 861-866, 2003.

[11] A. J. McMichael and T. Hanke, "HIV vaccines 1983-2003," Nature Medicine, vol. 9, no. 7, pp. 874-880, 2003.

[12] G. J. Nabel, "Challenges and opportunities for development of an AIDS vaccine," Nature, vol. 410, no. 6831, pp. 1002-1007, 2001.

[13] J. J. Donnelly, J. B. Ulmer, J. W. Shiver, and M. A. Liu, "DNA vaccines," Annual Review of Immunology, vol. 15, pp. 617-648, 1997.

[14] S. Gurunathan, D. M. Klinman, and R. A. Seder, "DNA vaccines: immunology, application, and optimization," Annual Review of Immunology, vol. 18, pp. 927-974, 2000.

[15] D. J. Shedlock and D. B. Weiner, "DNA vaccination: antigen presentation and the induction of immunity," Journal of Leukocyte Biology, vol. 68, no. 6, pp. 793-806, 2000.

[16] M. Dupuis, K. Denis-Mize, C. Woo, et al., "Distribution of DNA vaccines determines their immunogenicity after intramuscular injection in mice," Journal of Immunology, vol. 165, no. 5, pp. 2850-2858, 2000.

[17] R. Noad and P. Roy, "Virus-like particles as immunogens," Trends in Microbiology, vol. 11, no. 9, pp. 438-444, 2003.

[18] C. Yang, L. Ye, and R. W. Compans, "Protection against filovirus infection: virus-like particle vaccines," Expert Review of Vaccines, vol. 7, no. 3, pp. 333-344, 2008.

[19] Q. Yao, Z. Bu, A. Vzorov, C. Yang, and R. W. Compans, "Virus-like particle and DNA-based candidate AIDS vaccines," Vaccine, vol. 21, no. 7-8, pp. 638-643, 2003.

[20] M. F. Bachmann, U. H. Rohrer, T. M. Kundig, K. Burki, H. Hengartner, and R. M. Zinkernagel, "The influence of antigen 
organization on B cell responsiveness," Science, vol. 262, no. 5138, pp. 1448-1451, 1993.

[21] M. F. Bachmann, H. Hengartner, and R. M. Zinkernagel, "T helper cell-independent neutralizing B cell response against vesicular stomatitis virus: role of antigen patterns in B cell induction?" European Journal of Immunology, vol. 25, no. 12, pp. 3445-3451, 1995.

[22] L. Deml, G. Kratochwil, N. Osterrieder, R. Knüchel R, H. Wolf, and R. Wagner, "Increased incorporation of chimeric human immunodeficiency virus type 1 gp120 proteins into Pr55(gag) virus-like particles by an Epstein-Barr virus gp220/350derived transmembrane domain," Virology, vol. 235, no. 1, pp. 10-25, 1997.

[23] F. Notka, C. Stahl-Hennig, U. Dittmer, H. Wolf, and R. Wagner, "Accelerated clearance of SHIV in rhesus monkeys by virus-like particle vaccines is dependent on induction of neutralizing antibodies," Vaccine, vol. 18, no. 3-4, pp. 291-301, 1999.

[24] L. Deml, C. Speth, M. P. Dierich, H. Wolf, and R. Wagner, "Recombinant HIV-1 Pr55gag virus-like particles: potent stimulators of innate and acquired immune responses," Molecular Immunology, vol. 42, no. 2, pp. 259-277, 2005.

[25] L. X. Doan, M. Li, C. Chen, and Q. Yao, "Virus-like particles as HIV-1 vaccines," Reviews in Medical Virology, vol. 15, no. 2, pp. 75-88, 2005.

[26] Z. Bu, L. Ye, A. Vzorov, D. Taylor, R. W. Compans, and C. Yang, "Enhancement of immunogenicity of an HIV Env DNA vaccine by mutation of the Tyr-based endocytosis motif in the cytoplasmic domain," Virology, vol. 328, no. 1, pp. 62-73, 2004.

[27] G. V. Yamshchikov, G. D. Ritter, M. Vey, and R. W. Compans, "Assembly of SIV virus-like particles containing envelope proteins using a baculovirus expression system," Virology, vol. 214, no. 1, pp. 50-58, 1995.

[28] Q. Yao, F. M. Kuhlmann, R. Eller, R. W. Compans, and C. Chen, "Production and characterization of simian-human immunodeficiency virus-like particles," AIDS Research and Human Retroviruses, vol. 16, no. 3, pp. 227-236, 2000.

[29] Z. Bu, L. Ye, M. J. Skeen, H. K. Ziegler, R. W. Compans, and C. Yang, "Enhancement of immune responses to an HIV env DNA vaccine by a C-terminal segment of listeriolysin O," AIDS Research and Human Retroviruses, vol. 19, no. 5, pp. 409-420, 2003.

[30] L. Ye, Z. Bu, A. Vzorov, D. Taylor, R. W. Compans, and C. Yang, "Surface stability and immunogenicity of the human immunodeficiency virus envelope glycoprotein: role of the cytoplasmic domain," Journal of Virology, vol. 78, no. 24, pp. 13409-13419, 2004.

[31] M. B. Lutz, N. Kukutsch, A. L. J. Ogilvie, et al., "An advanced culture method for generating large quantities of highly pure dendritic cells from mouse bone marrow," Journal of Immunological Methods, vol. 223, no. 1, pp. 77-92, 1999.

[32] Q. Yao, R. Zhang, L. Guo, M. Li, and C. Chen, "Th cell-independent immune responses to chimeric hemagglutinin/simian human immunodeficiency virus-like particles vaccine," Journal of Immunology, vol. 173, no. 3, pp. 19511958, 2004.

[33] M. P. Girard, S. K. Osmanov, and M. P. Kieny, "A review of vaccine research and development: the human immunodeficiency virus (HIV)," Vaccine, vol. 24, no. 19, pp. 4062-4081, 2006.

[34] D. C. Montefiori, J. T. Safrit, S. L. Lydy, et al., "Induction of neutralizing antibodies and Gag-specific cellular immune responses to an R5 primary isolate of human immunodeficiency virus type 1 in rhesus macaques," Journal of Virology, vol. 75, no. 13, pp. 5879-5890, 2001.

[35] J. S. Boyle, A. Silva, J. L. Brady, and A. M. Lew, "DNA immunization: induction of higher avidity antibody and effect of route on T cell cytotoxicity," Proceedings of the National Academy of Sciences of the United States of America, vol. 94, no. 26, pp. 14626-14631, 1997.

[36] D. R. Drew, M. Lightowlers, and R. A. Strugnell, "Humoral immune responses to DNA vaccines expressing secreted, membrane bound and non-secreted forms of the Taenia ovis 45W antigen," Vaccine, vol. 18, no. 23, pp. 2522-2532, 2000.

[37] T. R. Mosmann and R. L. Coffman, "TH1 and TH2 cells: different patterns of lymphokine secretion lead to different functional properties," Annual Review of Immunology, vol. 7, pp. 145-173, 1989.

[38] D. R. Milich, F. Schodel, J. L. Hughes, J. E. Jones, and D. L. Peterson, "The hepatitis B virus core and e antigens elicit different Th cell subsets: antigen structure can affect Th cell phenotype," Journal of Virology, vol. 71, no. 3, pp. 2192-2201, 1997.

[39] S. Zhang, R. Cubas, M. Li, C. Chen, and Q. Yao, "Viruslike particle vaccine activates conventional B2 cells and promotes B cell differentiation to IgG2a producing plasma cells," Molecular Immunology, vol. 46, no. 10, pp. 1988-2001, 2009.

[40] S. Romagnani, M. H. Kaplan, and M. J. Grusby, "Understanding the role of Th1/Th2 cells in infection," Trends in Microbiology, vol. 4, no. 12, pp. 470-473, 1996.

[41] G. Gregoriadis, A. Bacon, W. Caparros-Wanderley, and B. McCormack, "A role for liposomes in genetic vaccination," Vaccine, vol. 20, supplement 5, pp. B1-B9, 2002.

[42] D. M. Da Silva, M. P. Velders, J. D. Nieland, J. T. Schiller, B. J. Nickoloff, and W. M. Kast, "Physical interaction of human papillomavirus virus-like particles with immune cells," International Immunology, vol. 13, no. 5, pp. 633-641, 2001.

[43] C. Ruedl, T. Storni, F. Lechner, T. Bachi, and M. F. Bachmann, "Cross-presentation of virus-like particles by skin-derived CD8- dendritic cells: a dispensable role for TAP," European Journal of Immunology, vol. 32, no. 3, pp. 818-825, 2002. 


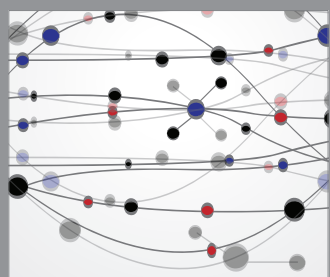

The Scientific World Journal
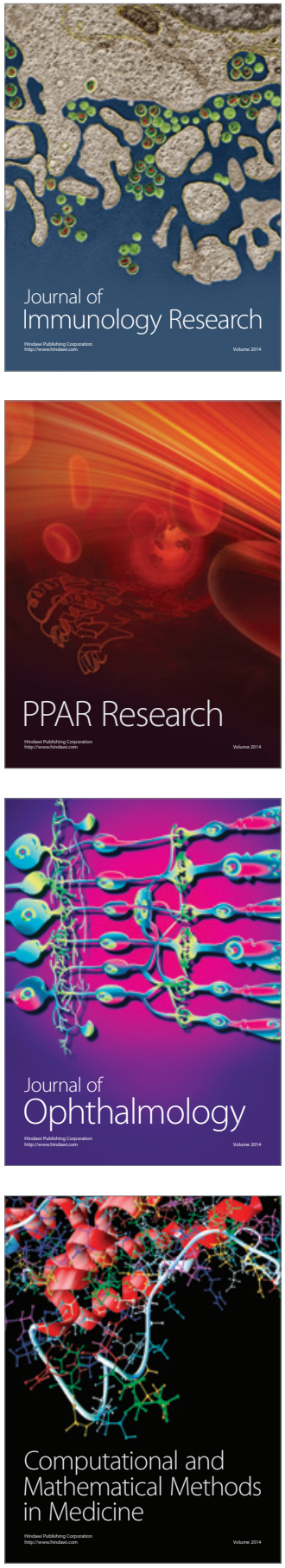

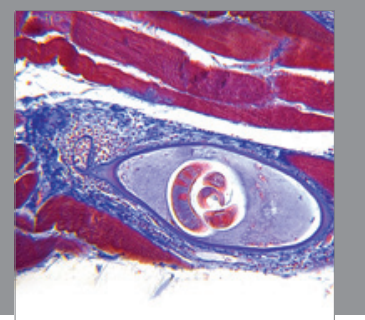

Gastroenterology

Research and Practice
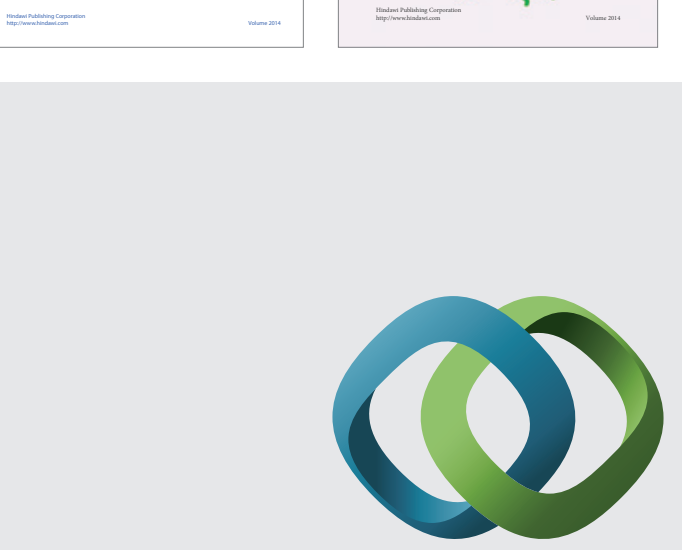

\section{Hindawi}

Submit your manuscripts at

http://www.hindawi.com
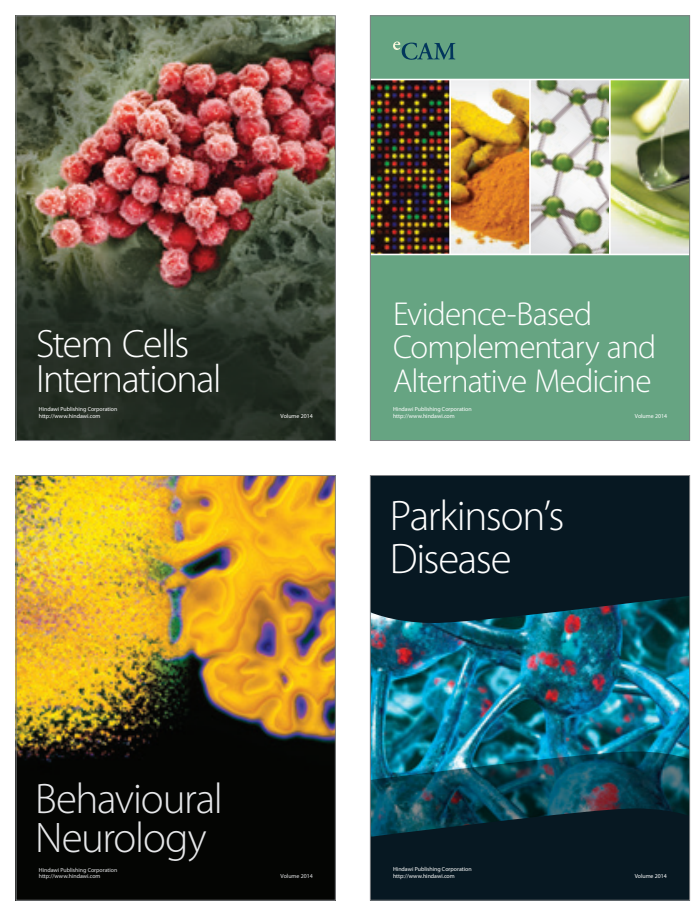

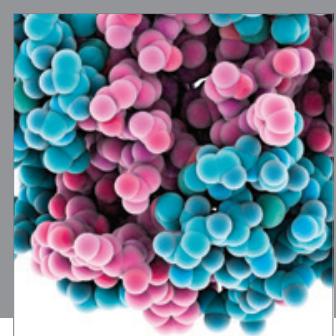

Journal of
Diabetes Research

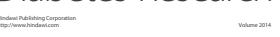

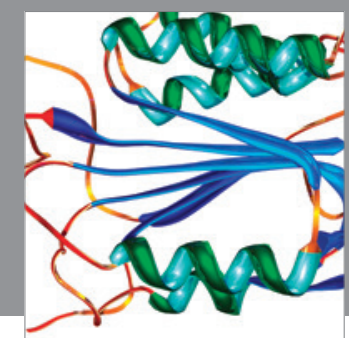

Disease Markers
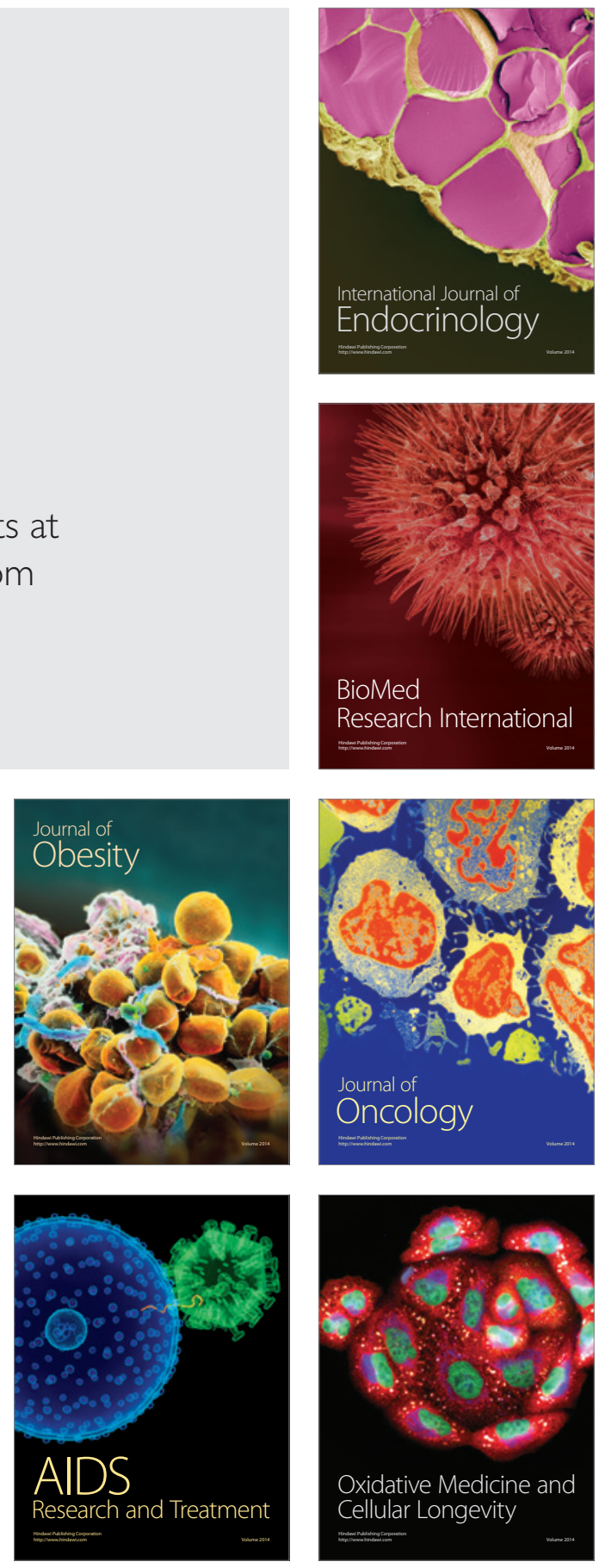